\title{
Frações nitrogenadas e de carboidratos e cinética ruminal da matéria seca e fibra em detergente neutro de silagens de Tifton 85 (Cynodon spp.)
}

\section{Carbohydrate and nitrogen fractions and ruminal kinetics of dry matter and neutral detergent fiber of Tifton 85 grass (Cynodon spp.) silages}

\author{
Elzânia Sales Pereira ${ }^{1 *}$; Alex Martins Varela de Arruda² $^{2}$ Ivone Yurika Mizubuti $^{3}$; \\ Maria Andréa Borges Cavalcante ${ }^{4}$; Edson Luis de Azambuja Ribeiro ${ }^{3}$; Sonia Maria \\ Pinheiro de Oliveira ${ }^{1}$; Bruno Mazzer de Oliveira Ramos ${ }^{5}$; Joaquim Bezerra Costa ${ }^{6}$
}

\section{Resumo}

\begin{abstract}
Avaliaram-se as frações nitrogenadas e de carboidratos e os parâmetros cinéticos de degradação da matéria seca (MS) e fibra em detergente neutro (FDN) de cinco silagens produzidas com Tifton 85: Tifton 85 exclusivo; Tifton 85 adicionado de resíduo de beneficiamento de milho; Tifton 85 adicionado de fubá de milho; Tifton 85 inoculado com Lactobacillus e Tifton 85 pré-seco. Os carboidratos totais variaram de 66,32 a 73,12\%; a fração B2 de 35,09 a 52,27 \%; e os carboidratos não estruturais de 8,61 a 38,03\%. Os valores obtidos para as frações protéicas variaram de 68,08 a 82,70\% para a fração A; de 1,14 a 2,97\% para a fração B1; de 7,46 a 13,71\% para a fração B2; de 6,09 a 12,60\% para a fração B3; e de 0,36 a $6,71 \%$ para a fração C. Os valores de degradação efetiva variaram de 46,93 a 63,49\% para MS; e de 33,47 a 37,84\% para FDN. A utilização de resíduos de beneficiamento de milho e fubá de milho para produção de silagens favoreceu a degradação efetiva da MS e FDN, proporcionando maior disponibilidade energética para microbiota ruminal.
\end{abstract}

Palavras-chave: Degradação, forrageiras, nutrição, ruminantes

\begin{abstract}
It was determined the nitrogen and carbohydrate fractions and dry matter (DM), and neutral detergent fiber (NDF) degradation kinetics in five silages prepared with Tifton 85 grass forage: exclusive Tifton 85, Tifton 85 silage added of corn industrial residue, Tifton 85 silage added of corn meal, Tifton 85 silage inoculated with lactobacillus and Tifton 85 silage pré-dry. The values of total carbohydrates varied from 66.32 to $73.12 \%$, the B2 fraction varied from 35.09 a $52.27 \%$; and non-structural carbohydrates varied from 8.61 to $38.03 \%$. The values obtained for the protein fractions varied from 68.08 to $82.70 \%$ for $\mathrm{A}$ fraction; from 1.14 to $2.97 \%$ for the $\mathrm{B} 1$ fraction; from 7.46 to $13.71 \%$ for the $\mathrm{B} 2$ fraction; from 6.09 to $12.60 \%$ for the $\mathrm{B} 3$ fraction; and from 0.36 to $6.71 \%$ for the $\mathrm{C}$ fraction. The values of effective degradability of dry matter varied from 46.93 to $63.49 \%$ for the DM, and from 33.47 to $37.84 \%$ for the NDF. The corn industrial residue and corn meal used for silage production favored the effective degradation of DM and NDF, and offered highest energy readiness for ruminal microorganisms.
\end{abstract}

Key words: Degradation, forages, nutrition, ruminants

\footnotetext{
1 Professora da Universidade Federal do Ceará, Depto de Zootecnia, Campus do Pici. Fortaleza, CE: E-mail: elzania@ hotmail.com.

2 Professor da Universidade Federal Rural do Semi-Árido, Depto de Ciência Animal, Mossoró, RN.

3 Universidade Estadual de Londrina (UEL), Depto. de Zootecnia, Londrina-PR. Pesquisadores do CNPq. E-mail:: mizubuti@uel.br.

4 Bolsista de DCR, Universidade Federal do Ceará, Depto de Zootecnia , Campus do Pici, Fortaleza, Ce.

5 Aluno de doutorado em Ciência Animal. Universidade estadual de Londrina (UEL). Londrina - PR.

6 Aluno de Mestrado da UFC, Depto de Zootecnia, Campus do Pici, Fortaleza, CE.

* Autor para correspondência
} 


\section{Introdução}

A alimentação dos ruminantes é um dos fatores responsáveis por grande parte dos custos variáveis de produção, dependendo das condições climáticas e do manejo alimentar empregado na propriedade. Dessa forma, as formulações de rações devem ser cuidadosamente ajustadas visando a máxima eficiência na produção animal. Para tanto, o conhecimento do comportamento dos alimentos no trato digestório é um fator importante para melhorar a eficiência de utilização da dieta.

A disponibilidade de nutrientes para os ruminantes depende da degradação realizada pelos microrganismos do rúmen. Por sua vez, o crescimento da população microbiana varia com as condições do ambiente ruminal, tais como temperatura, $\mathrm{pH}$, pressão osmótica, produtos da fermentação e baixa concentração de oxigênio. A cinética de degradação ruminal gera informações do processo de digestão que podem melhor descrever o valor nutritivo dos alimentos (VAN SOEST, 1994).

A natureza dos compostos nitrogenados presentes nos alimentos comumente empregados na alimentação dos ruminantes, influência a eficiência com a qual os microrganismos do rúmen utilizam o nitrogênio dietético. Logo, a eficiência de utilização do nitrogênio pelo hospedeiro também é influenciada.

Os sistemas de avaliação de alimentos para ruminantes que dão suporte a formulação de rações preconizam que os alimentos utilizados pelos animais sejam fracionados no sentido de melhor caracterizálos (SNIFFEN et al., 1992). A fração protéica dos alimentos pode ser fracionada em componentes $\mathrm{A}$ (fração constituída de compostos nitrogenados não protéicos), $\mathrm{B}_{1}$ (fração solúvel rapidamente degradada no rúmen), $\mathrm{B}_{2}$ (fração insolúvel, com taxa de degradação intermediária no rúmen), $\mathrm{B}_{3}$ (fração insolúvel lentamente degradada no rúmen) e fração C que é indigestível durante sua permanência no trato gastrintestinal. Os carboidratos também podem ser fracionados em componentes A (açúcares solúveis com rápida degradação ruminal), $\mathrm{B}_{1}$ (amido e pectina) e $\mathrm{B}_{2}$ (correspondente a fibra potencialmente degradável com taxa de degradação mais lenta) e C que apresenta característica de indigestibilidade. Este subfracionamento foi descrito por Sniffen et al. (1992), sendo objeto de entrada de dados para o sistema Cornell Net Carbohydrate and Protein System (CNCPS). Este sistema objetiva estimar taxas de degradação ruminal de diferentes subfrações dos alimentos, maximizar a sincronização de proteína e carboidratos no rúmen e conseqüentemente a produção microbiana, e ainda minimizar as perdas nitrogenadas (SNIFFEN et al., 1992).

A produção de leite no Oeste do Paraná baseiase na utilização das gramíneas tropicais como principal fonte de nutrientes. Estas gramíneas diferenciam-se das temperadas $\left(\mathrm{C}_{3}\right)$ quanto à eficiência de fixação de carbono, conferindo-as maior produção de matéria seca por unidade de área. Nos meses de novembro e dezembro na região do Oeste do Paraná ocorre um excedente na produção de capim Tifton 85, o que dificulta o processo de fenação em virtude de grande pluviosidade. Portanto, a ensilagem de capim Tifton 85 , nesta região do estado do Paraná, pode ser uma boa alternativa de conservação. Diante disso, o presente estudo teve como objetivo avaliar o fracionamento de carboidratos e proteínas conforme CNCPS, e a cinética ruminal da matéria seca e fibra em detergente neutro de diferentes silagens, produzidas a base de capim Tifton 85 (Cynodon spp.).

\section{Material e Métodos}

O Tifton 85, utilizado neste estudo, foi cultivado na fazenda experimental da Universidade Estadual do Oeste do Paraná - Unioeste, o qual foi colhido e picado em partículas de $3 \mathrm{~cm}$ e ensilado em silos experimentais, perfazendo cinco silagens experimentais: Tifton 85 exclusivo (STE); Tifton 85 adicionado de resíduo do beneficiamento do milho (STRB); Tifton 85 adicionado de fubá de milho (STFM); Tifton 85 inoculado com Lactobacillus (STL) e Tifton 85 pré-seco por uma hora e trinta 
minutos (STPS). A quantidade de resíduo do beneficiamento do milho e fubá de milho adicionado (16,5\%), foram calculados quantitativamente, com base em $100 \%$ da matéria seca, para obtenção de silagens com aproximadamente $32 \%$ de MS.

Inicialmente, as silagens foram analisadas para matéria seca (MS), matéria mineral (MM), matéria orgânica (MO), proteína bruta (PB) e extrato etéreo (EE) seguindo os procedimentos padrões (ASSOCIATION OF OFFICIAL ANALYTICAL CHEMISTS, 1990); e fibra em detergente neutro (FDN) e ácido (FDA) conforme Van Soest, Robertson e Lewis (1991). A fração A (NNP) foi determinada pela diferença entre o nitrogênio total e o nitrogênio insolúvel em ácido tricloroacético, o qual foi obtido através do tratamento de aproximadamente $500 \mathrm{mg}$ da amostra com $50 \mathrm{~mL}$ de água destilada, permanecendo em repouso por 30 minutos, e posteriormente adicionados $10 \mathrm{~mL}$ de ácido tricloroacético (TCA) a $10 \%$ por 30 minutos (LICITRA; HERNANDEZ; VAN SOEST, 1996). O resíduo remanescente foi filtrado em papel de filtro (Whatman, $\mathrm{n}^{\mathrm{o}} 54$ ), lavado com água e determinado o nitrogênio residual. O nitrogênio insolúvel total foi determinado a partir do tratamento de $500 \mathrm{mg}$ da amostra com tampão borato-fosfato $\left(\mathrm{NaH}_{2} \mathrm{PO}_{4} \cdot \mathrm{H}_{2} \mathrm{O}\right.$ à $12,2 \mathrm{~g} / \mathrm{L}+\mathrm{Na}_{2} \mathrm{~B}_{4} \mathrm{O}_{7} \cdot 10 \mathrm{H}_{2} \mathrm{O}$ à $8,91 \mathrm{~g} / \mathrm{L}+100 \mathrm{~mL} /$ L de álcool butílico terciário) durante 3 horas, sendo determinado o $\mathrm{N}$ residual. Pela diferença entre o nitrogênio total e o nitrogênio insolúvel total, foi obtido o nitrogênio solúvel total (NNP + proteína solúvel), do qual foi descontada a fração A para obtenção da fração $B_{1}$ (LICITRA; HERNANDEZ; VAN SOEST, 1996). A fração $B_{3}$ foi calculada pela diferença entre o nitrogênio insolúvel em detergente neutro (NIDN) e o nitrogênio insolúvel em detergente ácido (NIDA), os quais foram determinados através da fervura de $500 \mathrm{mg}$ da amostra com solução de detergente neutro e ácido durante uma hora, respectivamente, onde os resíduos foram também analisados para nitrogênio. A fração $\mathrm{C}$ foi considerada como sendo o nitrogênio insolúvel em detergente ácido (NIDA), e a fração $\mathrm{B}_{2}$ foi determinada pela diferença entre o nitrogênio total e as frações $\mathrm{A}, \mathrm{B}_{1}, \mathrm{~B}_{3}$ e $\mathrm{C}$.

Para obtenção do fracionamento dos carboidratos conforme o sistema CNCPS foram determinados os teores de nitrogênio total das amostras (NT), extrato etéreo e matéria mineral (ASSOCIATION OF OFFICIAL ANALYTICAL CHEMISTS, 1990). Os carboidratos totais foram determinados pela seguinte expressão: $\quad \mathrm{CT}=100-(\% \mathrm{~PB}+\% \mathrm{EE}+\% \mathrm{MM})$ (SNIFFEN et al., 1992). Os carboidratos não estruturais $\left(\mathrm{A}+\mathrm{B}_{1}\right)$ foram determinados pela expressão: $\mathrm{CNE}=$ $100-(\% \mathrm{~PB}+\% \mathrm{EE}+\% \mathrm{FDNcp}+\% \mathrm{MM})$, em que FDNcp equivale a parede celular corrigida para cinzas e proteínas. A fração $\mathrm{C}$ foi obtida através do resíduo indigestível após 96 horas de incubação com líquido ruminal; $a$ fração $\mathrm{B}_{2}$ foi determinada por diferença entre 100 - FDN remanescente após 96 horas de incubação.

Os parâmetros cinéticos de degradação ruminal da MS e FDN das silagens experimentais foram estimadas pela técnica do saco de náilon proposta por Orskov e McDonald (1979). Para tal, a moagem das silagens foi realizada com granulometria de 5 $\mathrm{mm}$. Pesou-se aproximadamente $5 \mathrm{~g}$ das amostras de silagens as quais foram colocados em sacos de náilon com dimensão de 7 x $14 \mathrm{~cm}$ com porosidade de $50 \mathrm{~mm}$, previamente secos em estufa com circulação forçada de ar a $55^{\circ} \mathrm{C}$ por 48 horas e pesados. Os sacos de náilon foram introduzidos no saco ventral do rúmen de cinco novilhos holandeses e incubados nos tempos de $0 ; 6 ; 24 ; 48 ; 72$ e 144 horas, conforme recomendado por Mertens (1993). Imediatamente após serem removidos do ambiente ruminal, foram colocados em balde com água fria para paralisação da atividade microbiana e então lavados em água corrente até que esta se mostrasse límpida. Os sacos correspondentes ao tempo zero hora (utilizados para determinar a fração prontamente solúvel) também foram lavados, juntamente com os demais, pré-secados e posteriormente pesados. Os parâmetros cinéticos da degradação da MS foram estimados utilizando-se o modelo descrito por Orskov e McDonald (1979): $Y=a+b\left(1-\mathrm{e}^{-c t}\right)$ onde: $\mathrm{Y}=$ degradação acumulada do componente nutritivo 
analisado, após um tempo t; $\mathrm{a}=$ intercepto da curva de degradação quando té igual a 0 , que corresponde a fração solúvel em água do componente nutritivo analisado; $b$ = potencial de degradação da fração insolúvel em água do componente nutritivo analisado; $\mathrm{a}+\mathrm{b}=$ degradação potencial do componente nutritivo analisado quando o tempo não é um fator limitante; c $=$ taxa de degradação por ação fermentativa de $b ; t$ = tempo de incubação. Uma vez calculados os coeficientes a, b, c, estes serão aplicados à equação proposta por Orskov e McDonald (1979):

$$
P=a+\frac{b \times c}{c+k},
$$

em que: $\mathrm{P}=$ degradação ruminal efetiva do componente nutritivo analisado; $\mathrm{k}=$ taxa de passagem do alimento. Assumiu-se uma taxa de passagem da digesta para o duodeno de $5 \%$ por hora, $\mathrm{k}=0,05 \%$.

Para a interpretação dos perfis de degradação da FDN, utilizou-se o modelo assintótico decrescente de primeira ordem, conforme Mertens (1993): Y= B $\exp ^{-{ }^{-\mathrm{T}}}+\mathrm{I}$, onde: $\mathrm{Y}=$ resíduo no tempo $\mathrm{t} ; \mathrm{B}=$ fração potencialmente degradável; $\mathrm{T}=$ tempos de incubação; c= taxa de degradação; $\mathrm{I}=$ fração não degradável. No ajustamento do modelo ao perfil de cada unidade experimental, visando à garantia de graus de liberdade suficiente para o procedimento interativo empregado, adotou-se a pressuposição de não solubilização ou não degradação da fração fibrosa do alimento instantaneamente.

Para realização dos ajustes, usou-se o processo interativo do algoritmo de Marquadt utilizando-se o programa SAEG - Sistema de Análises Estatísticas e Genéticas (UNIVERSIDADE FEDERAL DE VIÇOSA, 1997).

\section{Resultados e Discussão}

Os resultados referentes à composição bromatológica e os valores médios do fracionamento de carboidratos das silagens experimentais estão expressos na Tabela 1. Nota-se que STRB e STFM apresentaram superioridade para os CNE, registrando-se valores médios de 22,47 e $38,03 \%$, respectivamente, o que pode resultar em melhor adequação energética no rúmen.

Tabela 1. Composição química das silagens e valores médios do fracionamento de carboidratos das silagens experimentais (\% MS).

\begin{tabular}{cccccc}
\hline \multirow{2}{*}{ Componentes } & \multicolumn{5}{c}{ Silagens } \\
\cline { 2 - 6 } & STE $^{1}$ & STRB $^{2}$ & STFM $^{3}$ & STL $^{4}$ & STPS $^{5}$ \\
\hline MS & 23,66 & 33,17 & 33,79 & 24,35 & 30,97 \\
MO & 10,54 & 7,96 & 6,68 & 10,13 & 10,10 \\
PB & 89,46 & 92,04 & 93,32 & 89,87 & 89,90 \\
EE & 19,86 & 17,74 & 17,01 & 18,89 & 18,20 \\
FDN & 3,28 & 3,50 & 3,19 & 3,05 & 2,29 \\
FDA & 56,57 & 51,45 & 38,73 & 61,28 & 65,15 \\
FDNcp- Fração B2 & 35,37 & 28,34 & 21,89 & 34,49 & 34,57 \\
CT & 52,27 & 48,33 & 35,09 & 56,01 & 60,80 \\
CNE & 66,32 & 70,80 & 73,12 & 67,93 & 69,41 \\
& 14,05 & 22,47 & 38,03 & 11,92 & 8,61 \\
\hline
\end{tabular}

${ }^{1}$ Tifton 85 exclusivo (STE); ${ }^{2}$ Tifton 85 adicionado de resíduo do beneficiamento do milho (STRB); ${ }^{3}$ Tifton 85 adicionado de fubá de milho (STFM); ${ }^{4}$ Tifton 85 inoculado com Lactobacillus (STL); ${ }^{5}$ Tifton 85 pré-seco (STPS).

Os valores obtidos de FDNcp para as STE, STRB, STFM, STL foram, respectivamente, de 52,$27 ; 48,33 ; 35,09 ; 56,01$ e $60,80 \%$; sendo que a STPS, apresentou valores mais elevados para esta fração $(60,80 \%)$, podendo estar relacionado com o percentual de FDN $(65,15 \%)$, a qual foi superior as demais $(56,57,51,45,38,73$ e $61,28 \%$, respectivamente).

Considerando a relação inversa entre o teor de FDN e consumo, quando a ingestão é limitada pela repleção ruminal (MERTENS, 1987; MERTENS, 1994), pode-se inferir que a confecção de silagens 
com menores teores de FDN permitiriam maiores consumos. Consequientemente, o aumento do teor de CNE, teoricamente aumentaria o conteúdo em NDT, uma vez que estes carboidratos apresentam quase completa disponibilidade nutricional para os ruminantes (VAN SOEST, 1967; MERTENS, 1996), bem como a exigência em proteína degradada no rúmen para o atendimento do requisito em nitrogênio dos microrganismos que fermentam estes carboidratos (RUSSELL et al., 1992).
Quanto aos compostos nitrogenados (Tabela 2), representados pela fração A, as silagens STRB e STL destacaram-se com 82,70 e 79,45\% da PB, respectivamente, uma vez que durante a fermentação no silo, grande porção da proteína da planta, representada principalmente pela ribulose 1,4bisfosfato carboxilase (RUBISCO) é altamente susceptível à proteólise. Esta pode ser convertida a NNP (VAN SOEST, 1994), o que tem sido associado com elevadas perdas de $\mathrm{N}$.

Tabela 2. Valores médios do fracionamento dos compostos nitrogenados (A, B1, B2, B3 e C)

\begin{tabular}{cccccc}
\hline \multirow{2}{*}{ Frações Protéicas } & \multicolumn{5}{c}{ Silagens } \\
\cline { 2 - 6 } & STE $^{1}$ & STRB $^{2}$ & STFM $^{3}$ & STL $^{4}$ & STPS $^{5}$ \\
\hline A & 73,86 & 82,70 & 76,56 & 79,45 & 68,08 \\
B1 & 2,97 & 2,11 & 1,91 & 1,26 & 1,14 \\
B2 & 13,71 & 7,46 & 8,48 & 12,43 & 12,91 \\
B3 & 8,91 & 6,93 & 12,69 & 6,09 & 11,16 \\
C & 0,55 & 0,8 & 0,36 & 0,77 & 6,71 \\
\hline
\end{tabular}

${ }^{1}$ Tifton 85 exclusivo (STE); ${ }^{2}$ Tifton 85 adicionado de resíduo do beneficiamento do milho (STRB); ${ }^{3}$ Tifton 85 adicionado de fubá de milho (STFM); ${ }^{4}$ Tifton 85 inoculado com Lactobacillus (STL); ${ }^{5}$ Tifton 85 pré-seco (STPS).

Dos fatores predisponentes à proteólise, o teor de umidade e conseqüientemente, o pH elevado são os principais (VAN SOEST, 1994). Segundo Russell et al. (1992), fontes de NNP são fundamentais para o bom funcionamento ruminal, pois os microorganismos fermentadores de carboidratos estruturais presentes no rúmen, utilizam a amônia como fonte de $\mathrm{N}$ para síntese de proteína microbiana. Porém, altas proporções desta fração promovem grandes perdas de nitrogênio através da amônia.

A proporção de proteínas solúveis, rapidamente degradáveis no rúmen (B1), para as STE, STRB, STFM, STL e STPS variou de 1,14 a 2,97\%, respectivamente. A biomassa de bactérias ruminais que utiliza carboidratos não estruturais pode ser aumentada, quando ocorre disponibilidade da fração B1 no rúmen. Depois da fração $\mathrm{A}$, a fração B1 é a principal fração protéica das silagens. A fração B1 por apresentar rápida taxa de degradação ruminal relativa à fração $\mathrm{B} 3$, tende a ser extensivamente degradada no rúmen, contribuindo para o atendimento dos requisitos em $\mathrm{N}$ dos microrganismos deste compartimento (SNIFFEN et al., 1992).

A rápida proteólise da fração $\mathrm{B} 1$ no rúmen, também pode levar ao acúmulo de peptídeos e permitir o seu escape para os intestinos com a fase líquida, uma vez que a utilização de peptídeos tem sido referida como passo limitante à degradação de proteínas (WINTER; JOHNSON; DEHORITY, 1964). Nocek e Russell (1988) verificaram que, quanto mais elevados os valores das frações A e B1, maior a necessidade de suprimento de carboidratos de rápida degradação, para a obtenção de um adequado sincronismo na fermentação de carboidratos e proteínas no rúmen, levando ao melhor desempenho animal.

A fração B3 também é uma fração expressiva da proteína, entretanto, foi menor nas silagens produzidas com STRB e STL. Tal fração é representada pelas extensinas, as quais são proteínas de ligação da parede celular que apresentam lenta taxa de degradação, sendo, portanto, digeridas nos 
intestinos. Com relação à fração de proteínas insolúveis, não digeríveis no rúmen e intestinos (C), os valores para as silagens STE, STRB, STFM e STPS, variaram de 0,8 a $6,71 \%$. Segundo Van Soest (1994), 5 a $15 \%$ do $\mathrm{N}$ total das forragens encontramse ligados à lignina, sendo totalmente indisponível. Entretanto, os valores encontrados para as silagens, neste trabalho, estão abaixo desses limites estipulados por Van Soest (1994).
As estimativas dos coeficientes $a, b, c$ das equações ajustadas para a degradação da MS e FDN encontram-se nas Tabelas 3 e 4, respectivamente. Verifica-se que os valores do coeficiente "a" para a MS foram elevados para as STRB e STFM $(33,17$ e $31,02 \%$, respectivamente), fato este que pode estar relacionado com a adição do resíduo de beneficiamento de milho e fubá, promovendo o desaparecimento mais elevado desta fração quando comparada com as outras silagens.

Tabela 3. Coeficientes de degradação a, b, c da matéria seca das silagens, com seus respectivos coeficientes de determinação

\begin{tabular}{cccccc}
\hline \multirow{2}{*}{ Coeficientes de degradação } & \multicolumn{5}{c}{ Silagens } \\
\cline { 2 - 6 } & STE $^{1}$ & STRB $^{2}$ & STFM $^{3}$ & STL $^{4}$ & STPS $^{5}$ \\
\hline a & 14,66 & 33,17 & 31,02 & 18,14 & 14,09 \\
$\mathrm{~b}$ & 61,58 & 45,67 & 54,71 & 59,10 & 64,28 \\
$\mathrm{c}$ & 0,055 & 0,056 & 0,072 & 0,061 & 0,058 \\
$\mathrm{R}^{2}$ & 0,99 & 0,99 & 0,98 & 0,93 & 0,97 \\
\hline
\end{tabular}

${ }^{1}$ Tifton 85 exclusivo (STE); ${ }^{2}$ Tifton 85 adicionado de resíduo do beneficiamento do milho (STRB); ${ }^{3}$ Tifton 85 adicionado de fubá de milho (STFM); ${ }^{4}$ Tifton 85 inoculado com Lactobacillus (STL); ${ }^{5}$ Tifton 85 pré-seco (STPS)

Tabela 4. Coeficientes de degradação b, c, I da FDN das silagens, com seus respectivos coeficientes de determinação.

\begin{tabular}{cccccc}
\hline \multirow{2}{*}{ Coeficientes de degradação } & \multicolumn{5}{c}{ Silagens } \\
\cline { 2 - 6 } & STE $^{1}$ & STRB $^{2}$ & STFM $^{3}$ & STL $^{4}$ & STPS $^{5}$ \\
\cline { 2 - 6 } & 73,50 & 66,95 & 74,02 & 71,08 & 75,68 \\
$\mathrm{c}$ & 0,05 & 0,05 & 0,05 & 0,05 & 0,05 \\
$\mathrm{I}$ & 26,90 & 30,10 & 26,43 & 27,11 & 23,14 \\
$\mathrm{R}^{2}$ & 0,98 & 0,97 & 0,98 & 0,92 & 0,99 \\
\hline
\end{tabular}

${ }^{1}$ Tifton 85 exclusivo (STE); ${ }^{2}$ Tifton 85 adicionado de resíduo do beneficiamento do milho (STRB); ${ }^{3}$ Tifton 85 adicionado de fubá de milho (STFM); ${ }^{4}$ Tifton 85 inoculado com Lactobacillus (STL); ${ }^{5}$ Tifton 85 pré-seco (STPS).

Para a FDN, verifica-se pela Tabela 3 que todas as silagens apresentaram valores elevados para a fração potencialmente degradável, o que mostra alta disponibilidade de energia no ecossistema ruminal, pois os carboidratos são a principal fonte de energia tanto para os microrganismos do rúmen quanto para o animal hospedeiro, da qual, maior parte está contida nos constituintes da parede celular vegetal. Verificase que o valor do coeficiente $b$ apresentou variação para os diferentes tratamentos, porém estas oscilações podem ser atribuídas à própria composição das silagens e, preferência de microrganismos por diferentes tipos de tecidos.

Os carboidratos pela sua natureza química, e por questões físicas e anatômicas das gramíneas tropicais, são despolimerizados em uma taxa relativamente lenta pelos microrganismos do rúmen, o que, ou limita a ingestão de alimentos pela repleção dos compartimentos digestivos, ou limita o aproveitamento máximo do seu conteúdo energético (MERTENS, 1987). 
Quanto às taxas de degradação (c), observa-se que não houve variação entre as silagens, onde se registraram valores médios de $0,05 \%$.
Na Tabela 5, estão apresentadas as degradações efetivas da MS e FDN das silagens, considerando a taxa de passagem de $5 \% \mathrm{~h}$.

Tabela 5. Valores médios da degradação efetiva da matéria seca (MS) e fibra em detergente neutro (FDN) das silagens, expressos em percentagem.

\begin{tabular}{ccc}
\hline \multirow{2}{*}{ Silagens } & \multicolumn{3}{c}{ Degradação Efetiva } \\
\cline { 2 - 3 } & MS & FDN \\
\hline STE $^{1}$ & 46,93 & 36,75 \\
STRB $^{2}$ & 57,31 & 33,47 \\
STFM $^{3}$ & 63,49 & 37,01 \\
STL $^{4}$ & 50,69 & 35,54 \\
STPS $^{5}$ & 48,61 & 37,84 \\
\hline
\end{tabular}

${ }^{1}$ Tifton 85 exclusivo (STE); ${ }^{2}$ Tifton 85 adicionado de resíduo do beneficiamento do milho (STRB); ${ }^{3}$ Tifton 85 adicionado de fubá de milho (STFM); ${ }^{4}$ Tifton 85 inoculado com lactobacillus (STL); ${ }^{5}$ Tifton 85 pré-seco (STPS).

Os valores da degradação efetiva para a MS das silagens STE, STRB, STFM, STL e STPS, foram de 46,$93 ; 57,31 ; 63,49 ; 50,69$ e $48,61 \%$, respectivamente, valores estes próximos aos encontrados por Mouro et al. (2001), que registraram valores de 55,06\% para a silagem de milho. A degradação efetiva da FDN foi próxima àquela encontrada por Ferreira et al. (2001) que relataram valores de $28,84 \%$.

Malafaia, Valadares Filho e Vieira (1998), encontraram valores de $22,2 \%$ para a degradabilidade efetiva da FDN da silagem de milho e valores de $29,4 \%$ para o feno de Tifton 85 . No entanto, neste trabalho, a silagem produzida a partir do resíduo de beneficiamento de milho apresentou menor degradação efetiva registrando-se valores médios de $33,47 \%$. Este fato pode estar relacionado com a natureza gelatinosa do amido, que tem tendência a se aglutinar quando úmido, ocasionando menor exposição da área superficial da FDN (PEREIRA et al., 2000).

\section{Conclusão}

A utilização do resíduo de beneficiamento do milho e do fubá para produção de silagens favoreceu a degradação efetiva da matéria seca e da fibra em detergente neutro, proporcionando maior disponibilidade energética para a microbiota ruminal.

\section{Referências}

ASSOCIATION OF OFFICIAL ANALYTICAL CHEMISTS. Official methods of analysis. 15.ed. Arlington: AOAC, 1990. v.1.

FERREIRA, A. F.; JOBIM, C. C.; MARTINS, E. N.; GONÇALVES, G. D.; SANTOS, G. T.; CECATO, U. Estudo da cinética de degradação ruminal dos fenos de alfafa e de Tifton 85 e da silagem de milho. In: REUNIÃO ANUAL DA SOCIEDADE BRASILEIRA DE ZOOTECNIA, 38., 2001, Piracicaba. Anais... Piracicaba: SBZ, 2001. p.12661267.

LICITRA, G.; HERNANDEZ, T. M.; VAN SOEST, P. J. Standardization of procedures for nitrogen fractionation of ruminant feeds. Animal Feed Science Technology, Amsterdam, v.57, n.4, p.347-358, 1996.

MALAFAIA, P. A. M.; VALADARES FILHO, S. C.; VIEIRA, R. A. M. Determinação e cinética ruminal das frações protéicas de alguns alimentos para ruminantes. Revista Brasileira de Zootecnia, Viçosa, v.26, n.6, p.12431251, 1998.

MERTENS, D. R. Predicting intake and digestibility using mathematical models of ruminal function. Journal of Animal Science, Champaign, v.64, n.5, p.1548-1558, 1987. 
MERTENS, D. R. Rate and extent of digestion. In: FORBES, J. M.; FRANCE, J. (Eds.) Quantitative aspects of ruminant digestion and metabolism. Cambridge: $\mathrm{CAB}$ International, Cambridge University Press, 1993. p.13-51.

MERTENS, D. R. Regulation of forage intake. In: FAHEY JÚNIOR, G. C. (Ed.). Forage quality, evaluation, and utilization. Madison: American Society of Agronomy, 1994. p.450-493.

MERTENS, D. R. Using fiber and carbohydrate analysis to formulate dairy rations. Journal of Animal Science, Champaign, v.80, p.1463-1481, 1996.

MOURO, G. F.; BRANCO, A. F.; MAIA, F. J.; RIGOLON, L. P.; FERREIRA, R. A.; ALCALDE, C. R. Substituição do milho pela farinha de varredura em dietas de cabras em lactação; degradabilidade e fermentação ruminal. In: REUNIÃO ANUAL DA SOCIEDADE BRASILEIRA DE ZOOTECNIA, 38., 2001, Piracicaba. Anais... Piracicaba: SBZ, 2001. p.997-998.

NOCEK, J. E.; RUSSELL, J. B. Protein and energy as an integrated system. Relationship of ruminal protein and carbohydrate availability to microbial synthesis and milk production. Journal of Animal Science, Champaign, v.71, n.8, p.2070-2107, 1988.

ORSKOV, E. R.; McDONALD, I. The estimation of protein degradability in the rumen from incubation measurements weighted according to rate of passage. Jounal of Agricultural Science, New York, v.92, n.2, p.499-503, 1979.

PEREIRA, E. S. P.; PAIVA, P. C. A.; TIESENHAUSEN, I. M. E. V.; POZZA, P. C.; ARRUDA, A. M. V. Degradação da matéria seca, proteína bruta e fibra em detergente neutro de silagens de capim elefante adicionadas de resíduo de beneficiamento de milho e soja. Revista Brasileira de Zootecnia, Viçosa, v.29, n.6, p.2354-2358, 2000.
RUSSELL, J.B.; O'CONNOR, J.D.; FOX, D.G.; VANSOEST, P. J; SNIFFEN, C. J A net carbohydrate and protein system for evaluating cattle diets: I. Ruminal fermentation. Journal of Animal Science, Champaign, v.70, n.12, p.3551-3561, 1992.

SNIFFEN, C. J.; O'CONDOR, J. D.; VAN SOEST, P. J.; FOX, D. G.; RUSSELL, J. B. A net carbohydrate and protein system for evaluating cattle diets: II. Carbohydrate and protein availability. Journal Animal Science, Champaign, v.70, n.11, p.3562-3577, 1992.

UNIVERSIDADE FEDERAL DE VIÇOSA. Sistema para Análises Estatísticas e Genéticas - SAEG. Versão, 7.1. Viçosa: UFV, 1997.

VAN SOEST, P. J. Development of a comprehensive system of feeds analysis and its applications to forages. Journal of Animal Science, Champaign, v.26, p.119-128, 1967.

VAN SOEST, P. J. Nutritional ecology of the ruminant. 2.ed. Ithaca: Cornell University Press, 1994.

VAN SOEST, P. J.; ROBERTSON, J. B.; LEWIS, B. A. Methods for dietary fiber, neutral detergent fiber, and nonstarch polyssacharides in relation to animal nutrition. Journal of Animal Science, Champaign, v.74, n.10, p.35833597, 1991.

WINTER, K. A.; JOHNSON, R. R.; DEHORITY, B. A. Metabolism of urea nitrogen by mixed cultures of rumen bacteria grown on cellulose. Journal of Dairy Science, Champaign, v.47, p.793-797, 1964. 